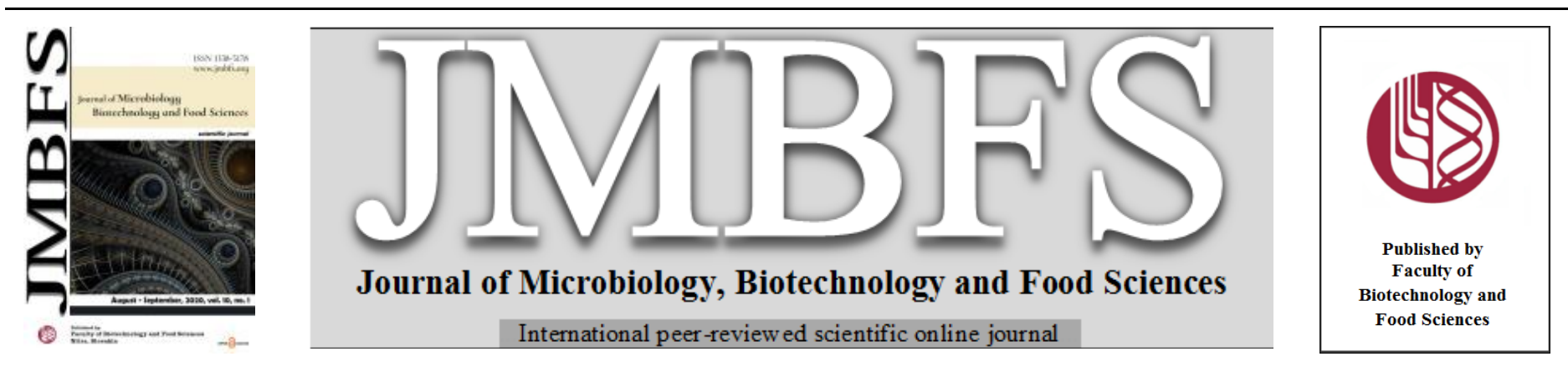

\title{
RESULTS OF IN VITRO ANDROGENESIS UNDER INCREASING SALINITY CONDITIONS FOR THREE MOROCCAN SPRING BARLEY VARIETIES (HORDEUM VULGARE L.)
}

\author{
Samira Hentour ${ }^{1}$, Younes El Goumi ${ }^{2}$, Rabouan Oubaidou ${ }^{l}$, Soukaina El Aanachi ${ }^{l}$, Sanah Essayagh ${ }^{l}$, Ouafa Lamsaouri ${ }^{l}$, Hafsa \\ Houmairi $^{1}$, Malika Fakiri ${ }^{1}$
}

$\operatorname{Address(es):~}$

${ }^{1}$ Laboratory of Agri-food and Health, Faculty of Sciences and Techniques, University Hassan $1^{\text {st }}$, BP 577, 26000, Settat, Morocco.

${ }^{2}$ Laboratory of Phyto-Biotechnology, National Agency of Medicinal and Aromatic Plant, B.P 159, Taounat, Morocco.

*Corresponding author: s.hentour@gmail.com

doi: 10.15414/jmbfs.2020.10.1.112-116

ARTICLE INFO

Received 19. 8. 2019

Revised 24. 3. 2020

Accepted 31. 3. 2020

Published 1. 8. 2020

Regular article

open $\partial_{\text {ACCESS }}$

\begin{abstract}
In vitro androgenesis process under salt pressure is recognized as being a valuable method for quick production of salt stress tolerant doubled haploid lines, enabling yield improvement of plants cultivated in dry climates. This study aimed to investigate the effect of salt stress on in vitro androgenetic regeneration, and the production of salt tolerant barley doubled haploid lines. Moroccan barley varieties, Arig, Asni and Tamelalt were used as RS0, and after one round of selfing (RS1) or two (RS2). These successive generations made possible to verify genetic stability or possible accidental heterozygosity, and to obtain plants presumably more tolerant to salinity. After culture of 11,340 anthers on induction medium, 2,270 calluses or embryos were generated. According to the induction rate of these formations, the three generations of each variety were not significantly different, pointing out the genetic stability after two selfings. Tamelalt and Arig had similar in vitro response, while for Asni, the three generations behaviour differed from the previous ones and constitute a statistically separate group. After transfer of the formations on regeneration medium either salt free, as control, or supplemented by increasing concentrations of $\mathrm{NaCl}$, ranging from 2.5 to $13 \mathrm{~g} . \mathrm{L}^{-1}, 170$ regenerants were produced. Asni (RS1) showed to be the most salt tolerant, bearing the maximal $\mathrm{NaCl}$ concentration of $12 \mathrm{~g} . \mathrm{L}^{-1}$, but the single regenerated plant obtained was albino, as most of the regenerated plants from any genotype and generation. However, RS1 and RS2 generations of Asni regenerated one green plant each, with $\mathrm{NaCl}$ concentration of $5 \mathrm{~g} . \mathrm{L}^{-1}$, resulting in two new Asni doubled haploid fertile lines.
\end{abstract}

Keywords: Androgenesis, $\mathrm{NaCl}$, salt stress, doubled haploids, calluses or embryos

\section{INTRODUCTION}

In arid and semi-arid regions, high soil salinity is one of the many abiotic stresses limiting the agricultural yields of wheat, rice, maize or barley. Soil salinity is the result of either irregular and insufficient rainfall, or strong evaporation of water. The drier is the climate, the more saline is the soil and higher the osmotic stress (Hillel et al., 2008), the two traits showing to be linked, it is then difficult for the roots to extract water from the soil, which results in weaker growth (De-Jongvan Lier et al., 2009). Hence, in cereals salt has a depressive effect on germination rates, biological growth and grain production (Bennaceur et al., 2001). Compared to wheat and rice, barley is considered to be the most salt tolerant; being rich in fibers, vitamins and hormones it is used for both animal and human nutrition and turns out to be one of the main cereals. Therefore, it appears interesting to develop a complementary research to use doubled haploid methods to obtain quickly improved salt tolerance new lines.

In vitro regeneration is largely demonstrated to be a source of variability for either somatic (Sibi, 1976) or gametophytic tissues (El-Goumi, 2015). In barley biometrical analyses of doubled haploid lines obtained through in vitro gynogenesis and androgenesis, show the last path to be source of wide variability (San Noeum and Ahmadi, 1982) and that is why in vitro anthers culture was chosen in this work.

In this species, after embryonic and plantlet stage, doubled haploid lines can be generated (Esteves, 2014) without any colchicine or other antimitotic treatments (Kahrizi and Mohammadi, 2009), as in barley spontaneous doubling is reaching up to 70 to $90 \%$ of the regenerated haploid plants (Devaux, 1998; Foroughi Wehr and Wenzel, 1993).

It should be emphasized that an environmental stress being applied during in vitro regeneration phase provides guidance of variability. The hypothesis herewith was that direct high level stress submission, as for rice tolerance to Alions (Van Sint Jan et al., 1997) or for barley to sodium chloride salt, i.e. $\mathrm{NaCl}$ (Guasmi et al., 2010), will eliminate every sensitive subject and select mainly monogenics mutants easy to revert, while a progressive and sub-lethal action should operate simultaneously gradual modifications at several hereditary levels, more difficult to be reverted (Sibi and Fakiri, 2000).

In this experiment, after the successive androgenesis steps, the doubled haploid barley regenerated on medium containing progressively increased $\mathrm{NaCl}$ concentrations, will constitute the first stage of a rapid creation of new barley lines for which, afterward, the tolerance to salt and drought will be analyzed, as well as agronomic traits.

Furthermore, during this first step, as the responses of the material might well be related to the genotype, three varieties entered the program to be compared during the in vitro phase, and because of the number of seeds necessary to repeat the experiments, three successive generations were made, thus by the way, the genetic homogeneity of each variety could be tested through the comparisons of the results at the same level, permitting to exclude the hypothesis of accidental residual heterozygosity.

\section{MATERIAL AND METHODS}

\section{Technical processes}

The plant material consisted of three spring barley fixed varieties $(2 n=14)$, Asni (As) and Tamelalt (Tm) with two rows, and Arig (Ar) with six rows, provided by INRA-Settat. This material was stated as RS0 (before selfing), RS1, after one round of natural self-fertilization and RS2, after two rounds. To simplify the global name of each case, for example, Tamelalt before selfing, will be written as "Tm RS0", and considered as a "category", giving for the three varieties a total of nine categories.

All the donor plants were grown in $20 \mathrm{~cm}$ diameter pots, containing seven grains per pot, and cultivated in the glasshouse. The spikes harvested at microspore uninucleated stage, were covered by filter paper soaked with water, wrapped in aluminum foil, and kept in refrigerator at $4^{\circ} \mathrm{C}$ for 14 days cold pretreatment (ElGoumi et al., 2017; Hentour et al., 2016; Kahrizi et al., 2011; Powell, 1988) to induce androgenesis and increase embryos yields. 
These spikes were sterilized by using $95^{\circ}$ ethanol. Glumes and husks were removed, and the anthers were extracted with sterile tweezers and placed on one side (El-Goumi, 2015; El-Goumi $\boldsymbol{e}$ al., 2017) at a density of one spike per $55 \mathrm{~mm}$ diameter Petri dishes containing induction FHG (Hunter, 1988) medium supplemented by $2 \mathrm{mg} . \mathrm{L}^{-1}$ of naphthaleneacetic acid (ANA) at pH 5.7. Every medium was sterilized by autoclaving at $120^{\circ} \mathrm{C}, 1 \mathrm{bar}$, for 20 minutes. The inoculated dishes were sealed with Parafilm and incubated at $25^{\circ} \mathrm{C}$ for 4 to 8 weeks, in the dark chamber.

Progressively, a total of 11,343 anthers followed this process enabling the development of 2,273 calluses or embryos, i.e. formations. When ranging from 1 to $2 \mathrm{~mm}$, the formations (El-Goumi, 2015) were gradually transferred in $90 \mathrm{~mm}$ diameter Petri dishes containing regeneration FHG medium at $\mathrm{pH} 5.8$, supplemented with $35 \mathrm{~g} . \mathrm{L}^{-1}$ of sucrose, and $0.4 \mathrm{mg} . \mathrm{L}^{-1}$ of benzyl amino purin (BAP).

Simultaneously with control cultures on salt free regeneration medium, according to Figure 1, increasing concentrations of $\mathrm{NaCl}$ were progressively added to this medium, up to the sub-lethal concentration. After one to two weeks, they generated either green or albino haploid plantlets.

The green ones were transferred to FHG rooting medium containing 20 g.L $\mathrm{L}^{-1}$ of sucrose. Once rooted, the plants were transplanted into $7 \mathrm{~cm}$ diameter pots containing sand and potting soil $(2 / 3,1 / 3)$ to ensure development and tillering, thus the progeny.

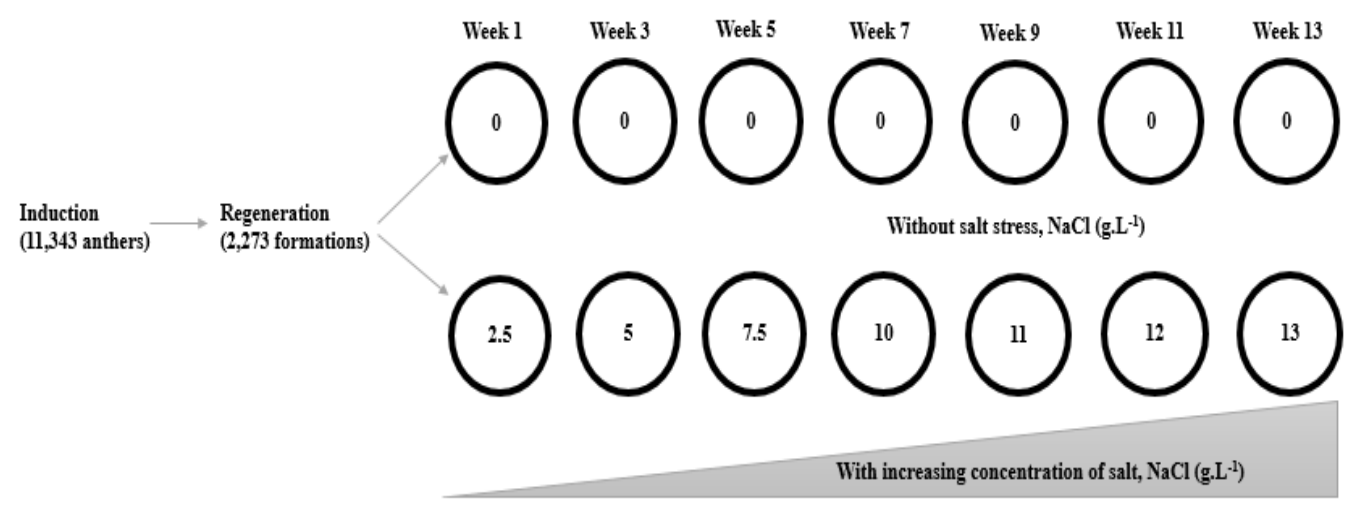

Figure 1: Experimental design

Legend: After the induction phase, the calluses or embryos (formations) were placed on regeneration medium. During the whole experiment, control dishes consisted of cultures on salt free medium. In parallel, the formations were placed on the same regeneration medium containing at the beginning $2.5 \mathrm{~g} . \mathrm{L}^{-1}$ of NaCl. Every two weeks transfer was made on new fresh medium supplemented by the increasing salt concentrations of 5, 7.5, 10, 11, 12 and 13 g.L. $L^{-1}$; up to 10 g. $L^{-1}$ a gap of 2.5 g. $L^{-1}$ was used, beyond $10 \mathrm{~g} . \mathrm{L}^{-1}$ of $\mathrm{NaCl}$ a $1 \mathrm{~g} . \mathrm{L}^{-1}$ increment was applied.

\section{Statistical analyses}

The following parameters were calculated:

- Induction rate $(\mathbf{I \%})=$ (number of responding anthers/number of cultured anthers) $\times 100$

- Regeneration rate out of embryos $(\mathbf{R} \%)=$ (total number of regenerated plants / number of cultured embryos) x 100

- Albinos rate out of total plants $(\mathbf{A} \%)=$ (number of albino plants / total number of regenerated plants) $\times 100$

\section{Several analyses were made:}

- The induction rates were ranked according to Duncan's multiple range tests $(\mathrm{p}<0.05)$ (Duncan, 1955) with SPSS software (Table 1).

- The ratios in percent of the total regenerated plants and of the albinos were listed in Table 2, while the numbers of green or albino plants were presented in Table 3 .

- To examine the combined effects of the genotypes and salt stress on regeneration or albinism, the data were statistically analyzed by $\chi^{2}$ test, using SPSS software (Table 4).

A p value $<0.05$ is considered as statistically significant.

\section{RESULTS}

\section{Induction phase}

The induction rates comparisons of the 2,243 formations issued from the 11,343 anthers for the three genotypes are presented in the Table 1
Table 1 Comparison of the induction rates in percent, according to the category, after Duncan's multiple range test

\begin{tabular}{lcll}
\hline Genotype & I\% group 1 & I\% group 2 & I\% group 3 \\
\hline Ar RS1 & 1.26 & & \\
Ar RS0 & 1.42 & & \\
Tm RS0 & 2.05 & & \\
Tm RS1 & 2.37 & & \\
Ar RS2 & 3.73 & 3.73 & \\
Tm RS2 & 4.15 & 4.15 & \\
As RS0 & & 9.29 & 9.29 \\
As RS2 & & & 13.97 \\
As RS1 & & & 14.07 \\
\hline Significance (p) & 0.377 & 0.060 & 0.106 \\
\hline
\end{tabular}

Symbols:

Genotypes: Ar: Arig, As: Asni, Tm: Tamelalt

Categories: RS0: before selfing, RS1: $1^{\text {rst }}$ generation from selfing, RS2: $2^{\text {nd }}$ generation from selfing

I\%: Induction rate of formations, the values are presented in $\%$ of anthers cultivated

Legend: The three groups 1, 2 and 3 can be distinguished by the ability to induce formations. In a same group the values do not differ significantly.

After Duncan analysis three groups were observed. The recorded rates of formations expressed by Arig were ranging from $1.26 \%$ for Ar RS1, to 3.73\% for Ar RS2, and those expressed by the three Tamelalt generations from $2.05 \%$ for Tm RS0 to $4.15 \%$ for Tm RS2, even if this last generation value is slightly higher, all of them being not statistically different belong to the group 1 .

However, Asni exhibited significantly higher rates of induction, with $9.29 \%$ for As RS0, $13.97 \%$ for As RS2 and $14.07 \%$ for As RS1, the three generations being linked statistically and constituting the group 3 .

The group 2, including Ar RS2 (3.73\%), Tm RS2 (4.15\%) and As RS0 (9.20\%), showed statistical links with the groups 1 and 3 that differ from each other statistically.

\section{Regeneration phase}

As shown in the experimental design (Figure 1) the 2,273 formations obtained were progressively transferred from the induction medium to the salt free or to a saline regeneration medium. In both cases, either green plants or albinos were regenerated, and the total regeneration or albinos rates were evaluated and listed in Table 2. 
Table 2 Regeneration and albinos rates obtained for each category, developed on control or salt type regeneration medium

\begin{tabular}{|c|c|c|c|c|c|c|c|c|c|c|c|c|c|c|c|c|c|c|}
\hline \multirow{2}{*}{$\mathrm{NaCl}\left(\mathrm{g} . \mathrm{L}^{-1}\right)$} & \multicolumn{2}{|c|}{ Ar RS0 } & \multicolumn{2}{|c|}{ Ar RS1 } & \multicolumn{2}{|c|}{ Ar RS2 } & \multicolumn{2}{|c|}{ As RS0 } & \multicolumn{2}{|c|}{ As RS1 } & \multicolumn{2}{|c|}{ As RS2 } & \multicolumn{2}{|c|}{ Tm RS0 } & \multicolumn{2}{|c|}{ Tm RS1 } & \multicolumn{2}{|c|}{ Tm RS2 } \\
\hline & $\mathbf{R} \%$ & $\mathbf{A} \%$ & $\mathbf{R} \%$ & A\% & $\mathbf{R} \%$ & A\% & $\mathbf{R} \%$ & A\% & $\mathbf{R} \%$ & $\mathbf{A} \%$ & $\mathbf{R} \%$ & A\% & $\mathbf{R} \%$ & A\% & $\mathbf{R} \%$ & A\% & $\mathbf{R} \%$ & A\% \\
\hline $\mathbf{0}$ & 29.6 & 37.5 & 8.7 & 100 & 10 & 100 & 8.4 & 100 & 12.4 & 100 & 8.4 & 100 & 5.7 & 100 & 15.1 & 50 & 4.7 & 100 \\
\hline 2.5 & 3.7 & 100 & 0 & - & 0 & - & 4 & 100 & 2.9 & 100 & 0 & - & 0 & - & 0 & - & 0 & - \\
\hline 5 & 3.7 & 100 & 0 & - & 0 & - & 0.8 & 100 & 5.8 & 94.1 & 4 & 92.3 & 3.4 & 100 & 1.2 & 100 & 3.1 & 100 \\
\hline 7.5 & 3.1 & 100 & 0 & - & 0 & - & 0 & - & 0 & - & 0 & - & 0 & - & 0 & - & 0 & - \\
\hline 10 & 0 & - & 0 & - & 0 & - & 0.7 & 100 & 0.5 & 100 & 0.5 & 100 & 0 & - & 0 & - & 0 & - \\
\hline 11 & 0 & - & 0 & - & 0 & - & 0 & - & 0 & - & 0 & - & 0 & - & 0 & - & 0 & - \\
\hline 12 & 0 & - & 0 & - & 0 & - & 0 & - & 0.2 & 100 & 0 & - & 0 & - & 0 & - & 0 & - \\
\hline 13 & 0 & - & 0 & - & 0 & - & 0 & - & 0 & - & 0 & - & 0 & - & 0 & - & 0 & - \\
\hline
\end{tabular}

Symbols:

Genotypes: Ar: Arig, As: Asni, Tm: Tamelalt

Categories: RS0: before selfing, RS1: after one round of selfing and RS2: after two rounds of selfing

$\mathbf{R} \%$ : Regeneration rate out of the embryos, $\mathbf{A} \%$ : Albinos ratio out of the regenerated plants

The noticeable values are in bold

Legend: The outcomes are reported for each category. The total regenerants and the albinos ratios are given in percent, out of formations numbers, after culture on salt free or on the increasing salt concentrations medium.

In control conditions, the regeneration maximum rates were of $29.6 \%$ for Ar RS0, $12.4 \%$ for As RS1 and $15.1 \%$ for Tm RS1. But despite this efficiency, there was a high level of regenerated albinos, often reaching 100\%. Only Ar RS0 with $37.5 \%$ of albinism and Tm RS1 with $50 \%$ gave green plants.

After culture on saline medium, the higher regeneration values were expressed at $5 \mathrm{~g} . \mathrm{L}^{-1}$ salt stress, for As RS1 and As RS2, with the rates of $5.8 \%$ and $4 \%$, respectively, and for which albinism appeared at a level of $94.1 \%$ for As RS1 and $92.3 \%$ for RS2.
Most of the regenerants showed to be albino, however regeneration occurred in several salt concentrations values, up to $12 \mathrm{~g} . \mathrm{L}^{-1}$ as for As RS1 with a rate of $0.2 \%$.

Thus, whatever the control or salt conditions were, the total numbers of either albino or green plants have been listed in Table 3, showing a summarized view of the results.

Table 3 Number of green and albino plants regenerated under control and salt stress conditions, according to the genotype

\begin{tabular}{llllllll}
\hline & Salt free & & \multicolumn{3}{c}{ Salt stress } & \multicolumn{2}{c}{ Total numbers } \\
\hline Arig & Green & Albinos & Sum & Green & Albinos & Sum & 16 \\
Asni & 5 & 8 & $\mathbf{1 3}$ & 0 & 3 & $\mathbf{3}$ & $\mathbf{1 1 1}$ \\
Tamelalt & 0 & 69 & $\mathbf{6 9}$ & $\mathbf{2}$ & 40 & $\mathbf{4 2}$ & $\mathbf{4 3}$ \\
\hline Total numbers & 13 & 22 & $\mathbf{3 5}$ & 0 & 8 & $\mathbf{8}$ & $\mathbf{1 7 0}$
\end{tabular}

Legend: Numbers of regenerants inventoried for the salt free path and also for the cumulated results from the salt stress experiments. Among the total number of 170 regenerants, there were 150 albinos and 20 green plants.

Based on Table 3, the control path gave a total number of 117 regenerated plants for the 3 varieties, comprising 99 albinos and 18 green plants. The salt stress path generated 53 plants, out of which 51 were albinos, while 2 green plants were obtained for Asni, on the 5 g. $\mathrm{L}^{-1}$ of salt medium.

Table 4 Statistical analysis of genotype and salinity effect on regeneration and albinism by $\chi 2$ test

\begin{tabular}{|c|c|c|c|c|c|c|}
\hline & Effect & Genotype/NaCl & & $\mathrm{NaCl} / \mathrm{g}$ & & \\
\hline & Parameters & Control & $\mathrm{NaCl}$ & Arig & Asni & Tamelalt \\
\hline \multirow{3}{*}{ Reg } & $\chi^{2}$ Test & 79.520 & 48.988 & 44.000 & 305.452 & 219.750 \\
\hline & ddl & 2 & 12 & 1 & 1 & 1 \\
\hline & p-value & $0.0004^{* * *}$ & 0.213 & 0.142 & $0.049 *$ & $<000 * * *$ \\
\hline \multirow{3}{*}{ Alb } & $\chi^{2}$ Test & 6.000 & 1.143 & 4.000 & 5.000 & 2.000 \\
\hline & ddl & 2 & 12 & 1 & 1 & 1 \\
\hline & p-value & $<0001 * * *$ & 0.565 & 0.261 & 0.287 & 0.157 \\
\hline
\end{tabular}

\section{Symbols:}

Reg: Regeneration, Alb: Albinism

Genotype/NaCl: genotype response to salt stress (All genotypes cumulated)

$\mathrm{NaCl} /$ genotype: salinity effect on each genotype (All $\mathrm{NaCl}$ concentrations cumulated)

p-value: significance, $*$ : significant, $* * *$ : highly significant

The $\chi^{2}$ test showed a genotype effect most marked for the control without addition of salt, for regeneration and albinism. A statistically significant difference was noted between the control and salt stress $(\mathrm{p}<0.05)$ showing the adverse effect of salt.

For salt stress medium (cumulated results from all concentrations), Tamelalt and Asni varieties indicate significant results compared to Arig with p-values of $<000$ and 0.049 respectively. Furthermore, the $\chi^{2}$ test showed that the interaction between genotype and salt stress $(\mathrm{NaCl})$ indicates non-significant results, i.e. the same negative effect, on regeneration and albinism, with p-values of 0.213 and 0.565 respectively.

\section{DISCUSSION}

In this study, the genetic material was composed of the three varieties, Asni, Tamelalt and Arig, the level of homozygosity of which has been verified by INRA-Settat. Each variety was multiplied by two successive self-fertilizations in order to provide sufficient number of anthers and permitting at the same time to test the possible effect of accidental heterozygosity.

During the first phase, the experiments started with barley androgenesis on a salt free induction medium, as to initiate divisions in the microspores. Additionally, it should be noted that in order to maximize the reactivity, all the anthers have to be plated on only one side on the in vitro medium, as a previous work (Fakiri, 1995) showed that the anther wall acts as a filter, allowing higher androgenic 
division rates. The calluses or embryos, i.e. formations, developed were counted for each generation and variety. The data presented in Table 1, showed firstly that induction rates, relative to the number of cultivated anthers, exhibited values that do not differ statistically, for the three generations of each genotype, ranking from $1.26 \%$ to $3.73 \%$ for Arig, $2.05 \%$ to $4.15 \%$ for Tamelalt and from $9.29 \%$ to $14.07 \%$ for Asni. These results confirming the homogeneity of the successive generations by selfing; in other terms, at that step, genetic stability or homozygosity of the three varieties was expressed, avoiding any possible effect of accidental heterozygosity. Moreover, while Arig and Tamelalt varieties showed to be statistically similar with the lowest values, ranging from $1.26 \%$ to $4.15 \%$, Asni exhibited a separate position with the significantly highest rates, mentioned above, and showing the special behavior of this genotype.

The next regeneration phase concerning salt stress applications differed from the other works cited in the literature; indeed, most of them were made on somatic tissue cultures, with direct application of high salt concentrations in the medium, as for durum wheat (Akhtar et al., 2012) selecting single-gene traits. The progressive introduction of salt, proposed here, up to sub-lethal levels might well produce several other kinds of tolerances, implying multiple hereditary traits, differing from monogenic ones easy to be reverted (Sibi and Fakiri, 2000). So, here the stressing $\mathrm{NaCl}$ agent was introduced upon each transfer, according to increasing concentrations, in the regenerating medium, versus control, i.e. salt free culture.

Concerning the albino plants observed here, it should be emphasized that in spring barley, albinism is the essential problem for this species facing androgenesis (Caredda et al., 2004; Castillo et al., 2000; Hunter, 1988) Because of the high frequency of albinos developed on either control or salt stress medium (150 out of the 170 total regenerated plants), and often reaching $100 \%$, for the three varieties, every albino or green plants were counted and the data reported as ratios values in Table 2 , or as numbers of regenerated plants in Table 3 .

Thus for the control path, only Arig (Ar RS0) with $37.5 \%$ of albinism, and Tamelalt (Tm RS1) with 50\%, gave respectively 5 and 13 green plants, while every Asni regenerated plants were albino.

After in vitro culture on salt stress medium, all the regeneration rates appeared to be lower than those of the control path. Meanwhile, green plants results seem to depend on the limitation expressed by albinism. Then, with rates of $100 \%$ of albinos, among the 11 plants generated by Arig and Tamelalt, on until 10 g.L $\mathrm{L}^{-1}$ of salt in the medium, none were green. Furthermore, in spite of the regenerated plants obtained with Asni on salt concentrations values, up to 12 g. $\mathrm{L}^{-1}$, the only efficient green plants were obtained on $5 \mathrm{~g} . \mathrm{L}^{-1}$ of salt medium, for As RS1 and As RS2, with regeneration rates of $5.8 \%$ and $4 \%$, respectively, among which albinos rates were a little lower than $100 \%$, thus resulting in one chlorophyllian plant for each case. However, even if high sodium chloride concentrations showed an adverse effect on regeneration, it should be pointed out that in previous work, a fertile green regenerated plant of Tamelalt has been obtained with $15 \mathrm{~g} . \mathrm{L}^{-1}$ salt concentration in the medium (Sibi and Fakiri, 2000) suggesting that high concentrations values can be successfully applied.

After the three varieties did follow the successive androgenesis steps, the genotypic effects were clearly revealed at the different levels of the experiment this being consistent with many other works (Bennaceur, 2000; El-Goumi, 2015; El-Haddoury et al., 2000; Kahrizi et al., 2011) and remaining among the important factors for the induction of embryos (EI-Goumi et al., 2014; Kahrizi et al., 2011) and later, for the regeneration of green plants.

Albinism that seemed to be the main limiting factor should be studied more precisely. It should be noticed that six-rows barley like Arig showed to be considered as specially affected by albinism during in vitro androgenesis (ElGoumi et al., 2017; Esteves and Belzile, 2014). This problem appearing not only to be due to morphological disturbances of the chloroplasts, but also to their quantity (Caredda et al., 1999). Indeed, for regenerants from the microspores of concerned genotypes, lower numbers of chloroplasts have been observed, as well as a significant decrease of chloroplast-DNA copies per chloroplast (Caredda $\boldsymbol{e t}$ al., 2004); furthermore, at biochemical level, the lacking of chlorophyll a and b has also been reported (Asakaviciute et al., 2006). So serious disturbances seem to greatly affect the chorophyllian potentialities, leading to the development of albino plants.

\section{CONCLUSION}

This program herewith described has been proposed to obtain homozygous lines of barley tolerant to salinity and drought, traits that appear to be bound. The first phase carried out consisted of haploid regeneration through in vitro anthers culture on medium containing progressively increased $\mathrm{NaCl}$-salt concentrations Therefore with these experiments, new genotypes such as doubled haploid lines derived from Asni should be suited to salt and drought, and after being tested for their tolerance, able to be used in further breeding trials.

The efficiency of the experiments depends on a high induction rate of embryos associated with a low level of albinism. Considering these results, it appears that the first important point for further research will be to test a larger range of genotypes to overcome the different limiting factors as mainly, genotypic effect on embryos rate and on albinism.
Here whatever the albinos numbers were, a few regenerated green plants of Asni, developed on salt medium, were obtained and able to enter other further phases of this experiment. Being chlorophyllian and fertile, these doubled haploid plants, able to be grown, gave progenies. After one or further successive selffertilizations, the seeds produced could be used according to the following different ways. The same stages could be undertaken by the regenerants obtained on salt free conditions and constitute part of the controls for the next steps.

Besides, on the one hand, in situ later analyses could be focused on the intended increase of tolerance, through trials comparing the progenies issued from the regenerants developed in salt stress conditions, and those from both parental genotypes and salt free controls, the results supposing and verifying hereditary transmission of the tolerance traits.

On the other hand, a new cycle of in vitro androgenesis could be made again, using anthers of the doubled haploid lines already produced during the first phase presented here, with the aim that these new doubled haploid lines will produce higher rates of embryos and less albinism as described for bread wheat by PICARD and DE BUYSER (1977). Furthermore, gynogenesis or in vitro culture of ovaries could also be experimented, this way giving a low rate or absence of albinos (Hentour et al., 2016). Though in barley this technique is considered not to generate variability (San Noeum and Ahmadi, 1982), this assumption is based on direct regeneration of the ovaries on salt free medium. But here the transfer of the ovaries derived embryos obtained, on salt regeneration medium, and the in vitro conditions inducing an, even short, callus phase before plant regeneration (Sibi and Fakiri, 2000) could well produce the tolerant green doubled haploid plants desired, exhibiting an increased tolerance to salt.

These experiments show promising results for further utilization of androgenesis and gynogenesis, combined with salt stress, in order to provide improved elite lines (germplasm) for barley breeding in Morocco.

Acknowledgments: This research received no specific grant from any funding agency in the public, commercial, or not-for-profit sectors.

\section{REFERENCES}

Akhtar, S., Niaz, M., Ur-Rahman, S., Younas, M., and Iqbal, M. Z. (2012) Somaclonal Variation for Development of Salt Tolerance in Selected Wheat (Triticum aestivum) Cultivars. International Journal of Agriculture \& Biology, 14(4), 176-180.

Asakaviciute, R., Jacquard, C., and Clement, C. (2006). Study of chlorophyll a and $\mathrm{b}$ in etiolated and androgenic plants of barley (Hordeum vulgare L.). Journal of Stress Physiology \& Biochemistry, 2(1), 10-15.

Bennaceur, M. (2000). Callus formation and plant regeneration from young wheat spikes: Effect of genotypes. In : Royo C. (ed.), Nachit M. (ed.), Di Fonzo N. (ed.), Araus J.L. (ed.). Durum wheat improvement in the Mediterranean region: New challenges. In CIHEAM.

Bennaceur, M., Rahmoune, C., Sdiri, H., Meddahi, M., and Selmi, M. (2001) Effet du stress salin sur la germination, la croissance et la production en grains de quelques variétés maghrébines de blé. Science et Changements Planétaires Sécheresse, 12(3), 167-174.

Caredda, S., Devaux, P., Sangwan, R. S., and Clément, C. (1999). Differential development of plastids during microspore embryogenesis in barley. Protoplasma, 208(1-4), 248-256. https://doi.org/https://doi.org/10.1007/BF01279096

Caredda, S., Devaux, P., Sangwan, R. S., Proult, I., and Clément, C. (2004). Plastid ultrastructure and DNA related to albinism in androgenetic embryos of various barley (Hordeum vulgare) cultivars. Plant Cell, Tissue and Organ Culture, 76(1), 35-43. https://doi.org/10.1023/A:1025812621775

Castillo, A. M., Vallés, M. P., and Cistué, L. (2000). Comparison of anther and isolated microspore cultures in barley. Effects of culture density and regeneration medium. Euphytica, 113(1), 1-8. https://doi.org/10.1023/A:1003937530907

De-Jong-van Lier, Q., van Dam, J. C., and Metselaar, K. (2009). Root Water Extraction under Combined Water and Osmotic Stress. Soil Science Society of America Journal, 73(3), 862-875. https://doi.org/10.2136/sssaj2008.0157

Devaux, P. (1998). Les plantes haplö̈des chez l'orge, avec extension au blé: méthodes d'obtention et relations avec l'organisation de leur génome. Diss. Lille 1.

Duncan, D. B. (1955). Multiple Range and Multiple F Tests. Biometrics, 11(1), 1-42. https://doi.org/0.2307/3001478

El-Goumi, Y. (2015). Androgenèse in vitro en conditions d'application progressive de stress salin chez trois cultivars d'orge marocaine (Hordeum vulgare ssp. vulgare) Approche pour la création de tolérance à la salinité. Université HassanI, Faculté des sciences et techniques, Settat.

El-Goumi, Y., Fakiri, M., Benbachir, M., Essayagh, S., and Lamsaouri, O. (2017). Effest of Cold Pretreatment, Anthers Orientation, Spikelet Position an Donor Tiller on the Callusing Response in Barley Anther In vitro Culture. International Journal of Medical Biotechnology \& Genetics, S2(003), 33-38.

El-Goumi, Y., Fakiri, M., Lamsaouri, O., Benchekroun, M., and Hassani, M. F. (2014). Analyse de la capacité androgénétique de trois cultivars de blé dur (Triticum durum) et trois cultivars de blé tendre (Triticum aestivum). Lebanese 
Science Journal, 15(1), 85-98.

El-Haddoury, J., Amri, A., Baidani, A., Chlyah, H., and Nsarellah, N. (2000). Étude de la réponse à l'androgenèse in vitro des lignées de substitution disomique chez le blé dur. Comptes Rendus de l'Academie Des Sciences - Serie III, 323(3), 251-255. https://doi.org/10.1016/S0764-4469(00)00131-1

Esteves, P. (2014). Optimisation de la culture de microspores isolées chez les orges de printemps à six rangs. Université LAVAL. Québec, Canada.

Esteves, P., and Belzile, F. (2014). Improving the efficiency of isolated microspore culture in six-row spring barley: I-optimization of key physical factors. Plant Cell Reports, 33(6), 993-1001. https://doi.org/10.1007/s00299014-1583-X

Fakiri, M. (1995). Obtention chez l'orge (hordeum vulgare) de regeneration par androgenese et gynogenese in vitro en conditions de stress salin. Application a trois genotypes marocains. Vandoeuvre-les-Nancy, INPL.

Foroughi Wehr, B., and Wenzel, G. (1993). Andro-and parthenogenesis. In Plant Breeding (pp. 261-277). Springer. https://doi.org/https://doi.org/10.1007/978-94011-1524-7_18

Guasmi, F., Elfalleh, W., Marzougui, N., Triki, T., and Ferchichi, A. (2010) Création de variétés tolérantes au stress abiotique chez l'orge (Hordeum vulgare L.) par culture d'anthères. Acta Botanica Gallica, 157(3), 445-450. https://doi.org/10.1080/12538078.2010.10516221

Hentour, S., El Goumi, Y., Fakiri, M., Lamsaouri, O., Benbachir, M., and Benchekroun, M. (2016). Effect of cold and mannitol pretreatment on the androgenesis and gynogenesis in spring barley varieties (Hordeum vulgare L.). Journal of Materials and Environmental Science, 7(7), 2583-2594.

Hillel, D., Braimoh, A. K., and Vlek, P. L. G. (2008). Soil degradation under irrigation. In Land Use and Soil Resources (pp. 101-119). Netherlands, Springer. https://doi.org/https://doi.org/10.1007/978-1-4020-6778-5_6

Hunter, C. P. (1988). Plant regeneration from microspores of barley Hordeuni vulgare L. University of London. Wye College, Ashford, Kent.

Kahrizi, D., Mahmoodi, S., Khaniki, G. B., Mirzaei, M., and Kahrizi, D. (2011) Effect of genotype on androgenesis in barley (Hordeum vulgare L.). Biharean Biologist, 5(2), 132-134.

Kahrizi, D., and Mohammadi, R. (2009). Study of androgenesis and spontaneous chromosome doubling in barley ( Hordeum vulgare L.) genotypes using isolated microspore culture. Acta Agronomica Hungarica, 57(2), 155-164. https://doi.org/10.1556/AAgr.57.2009.2.7

PICARD, E., and DE BUYSER, J. (1977). High production of embryoids in anther culture of pollen derived homozygous spring wheats. Annales de l'amélioration Des Plantes, 27(4), 483-488.

Powell, W. (1988). Diallel analysis of barley anther culture response. Genome, 30(2), 152-157. https://doi.org/10.1139/g88-026

San Noeum, L. H., and Ahmadi, N. (1982). Variability of doubled haploids from in vitro androgenesis and gynogenesis in Hordeum vulgare, L. In Variability in Plants Regenerated from Tissue Culture (pp. 273-283). Praeger.

Sibi, M. (1976). La notion de programme génétique chez les végétaux supérieurs. II Aspect expérimental : obtention de variants par culture de tissus in vitro sur Lactuca sativa L., apparition de vigueur chez les croisements. Annales de l'amélioration Des Plantes, 26(4), 523-547.

Sibi, M., and Fakiri, M. (2000). Androgenèse et gynogenèse, sources de vitrovariation et de tolérance à la salinité chez l'orge Hordeum vulgare? Science et Changements Planétaires/Sécheresse, 11(2), 125-132.

Van Sint Jan, V., Costa de Macedo, C., Kinet, J.-M., and Bouharmont, J. (1997) Selection of Al-resistant plants from a sensitive rice cultivar, using somaclonal variation, in vitro and hydroponic cultures. Euphytica, 97(3), 303 https://doi.org/10.1023/A:1003045929279 